\title{
Diffusion Combustion during Interaction of a Supersonic Round Microjet of Air with a Coaxial (Coflowing Ring) Jet of Hydrogen
}

\author{
V. V. Kozlov ${ }^{a, b}, *$, M. V. Litvinenko ${ }^{a, b}$, Yu. A. Litvinenko ${ }^{a}$, \\ A. S. Tambovzev ${ }^{a, b}$, and A. G. Shmakov ${ }^{b, c}$ \\ Presented by Academician S.V. Alekseenko November 27, 2020
}

Received December 4, 2020; revised December 4, 2020; accepted December 18, 2020

\begin{abstract}
The results of experimental investigations of the features of diffusion combustion during the interaction of a round supersonic microjet of air in the center and a coaxial (coflowing ring) jet of hydrogen. Such combustion is accompanied by a number of new phenomena: the formation of a cone-shaped flame near the nozzle cutoff, the locking of the combustion region in this cone, the presence of small-scale supersonic cells in the resulting flow, and the formation of laminar sections and their turbulization.
\end{abstract}

Keywords: round microjet of air, coaxial jet of hydrogen, bottleneck-flame region, small-scale shock cells DOI: $10.1134 / \mathrm{S} 102833582102004 \mathrm{X}$

According to results of [1-5], the following combustion scenarios are characteristic for hydrogen flowing from round nozzles with diameters $d=250-$ $500 \mu \mathrm{m}$ depending on the flow rate $U_{0}$ : (i) a large length of the laminar jet ( $\left.U_{0} \leq 150 \mathrm{~m} / \mathrm{s}\right)$; (ii) the separation of the flame into two zones by a "bottleneck" of flame, the formation of a spherical zone with the laminar combustion character, and the turbulization of the flame further upstream $\left(U_{0} \sim 150 \mathrm{~m} / \mathrm{s}\right)$; (iii) the implementation of an elevated turbulent flame with preservation of combustion in the laminar zone; (iv) the preservation of combustion in the laminar flame region and the turbulent flow of hydrogen further along the stream without combustion $\left(U_{0} \sim 331 \mathrm{~m} / \mathrm{s}\right)$; and $(\mathrm{v})$ the termination of microjet combustion $\left(U_{0}>\right.$ $331 \mathrm{~m} / \mathrm{s})$.

The spherical region of the flame with the laminar flow and combustion in it, which covers the upper part of the nozzle, contributes to the stabilization of the combustion process in the hydrogen microjet but also promotes the "locking" effect of the nozzle, while the flow rate does not exceed subsonic values.

\footnotetext{
${ }^{a}$ Khristianovich Institute of Theoretical and Applied Mechanics, Siberian Branch, Russian Academy of Sciences, Novosibirsk, 630090 Russia

${ }^{b}$ Novosibirsk State University, Novosibirsk, 630090 Russia

${ }^{c}$ Voevodsky Institute of Chemical Kinetics and Combustion, Siberian Branch, Russian Academy of Sciences, Novosibirsk, 630090 Russia

*e-mail:kozlov@itam.nsc.ru
}

One of the characteristics of supersonic jet flow is the presence of supersonic cells, which are also preserved in the resulting flow during combustion but in the situation of a flame rising from the nozzle cutoff. This situation was demonstrated in detail in [6-8]. The results of experimental and numerical investigations of combustion of round hydrogen jets at subsonic and supersonic flow rates are presented in detail in [9-11].

In $[12,13]$, attention was paid to the combustion of premixed hydrogen with oxygen, methane, nitrogen, and helium. The range of velocities at which the combustion without flame failure existed was smaller than in the case of pure hydrogen. Nevertheless, by adding hydrogen, it is possible to extend the range of sustained combustion of methane and other hydrocarbons. In this case, the microjet combustion of a mixture of hydrogen and various gases was investigated under conditions of their mixing before the mixture was introduced into the nozzle apparatus. The coaxial jets and precisely their interaction were investigated in considerably fewer works, especially experimental ones. The theoretical study in [14] shows the development of a coaxial jet at subsonic and supersonic velocities and numerically simulates the presence of supersonic cells during the supersonic flow of a coaxial jet.

The aim of this study is to investigate the features of development and interaction between a round microjet of air flowing at supersonic velocity and a coaxial (coflowing ring ) hydrogen jet during its combustion. 


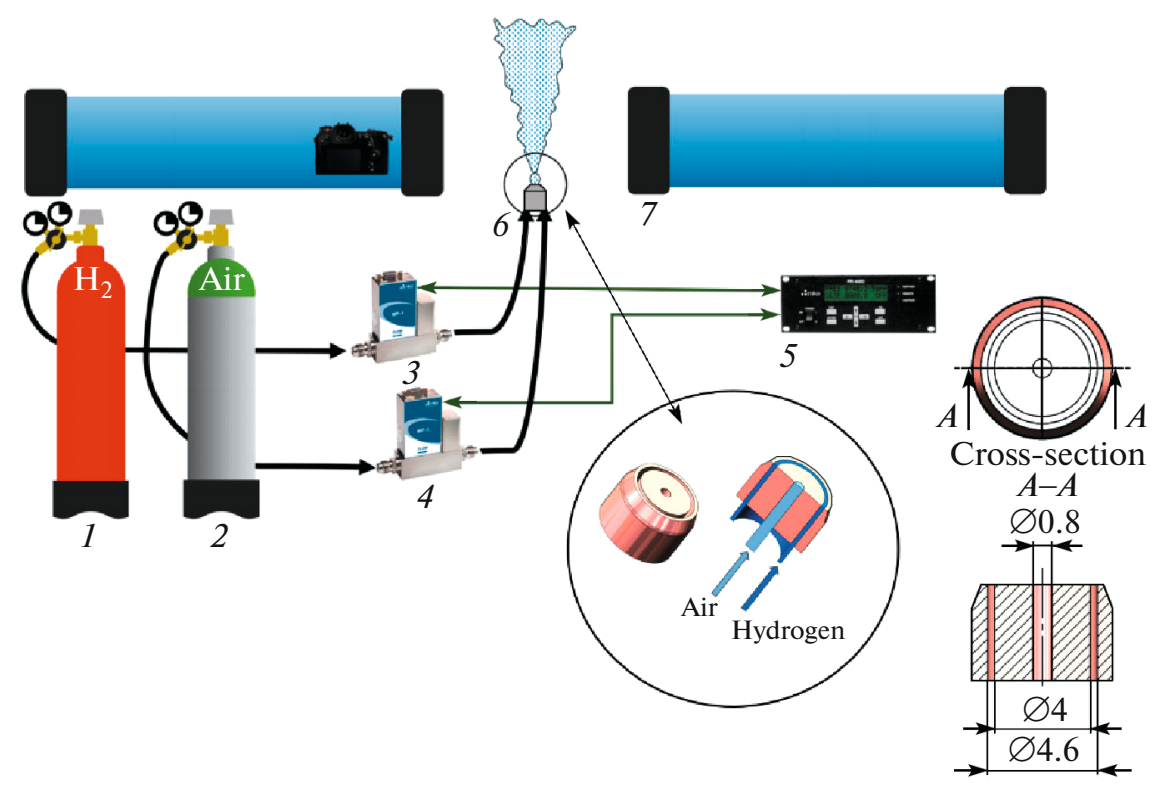

Fig. 1. Schematic representation of the experiment: 1 is hydrogen, 2 is air, 3 and 4 are the gas-flow regulators, 5 is the flow-meter control unit, 6 is the nozzle device, and 7 is the Tepler shadow device.

\section{EXPERIMENTAL EQUIPMENT AND INVESTIGATION PROCEDURE}

Figure 1 shows a schematic representation of the experiment. Nozzle apparatus 6 is connected to two similar gas lines. From the cylinders, the gas (hydrogen (1) or air (2)) goes to valves 3, 4 of an MKS Instruments type 1179B volume flow-rate regulator, which provides an accuracy of flow-rate measurement within $0.7 \%$; with help of a PR 4000B-F (MKS Instruments) two-channel flow-meter control unit, the flow rate of the gases fed into the nozzle apparatus is controlled. The shadow pattern was obtained using IAB-451 (7), and the shadow pattern image is recorded on a digital video camera. The parameters of the nozzle-apparatus orifices are the following: $S_{1}=0.5 \mathrm{~mm}^{2}$ is the crosssection area of the outlet orifice for air $(\varnothing=0.8 \mathrm{~mm})$

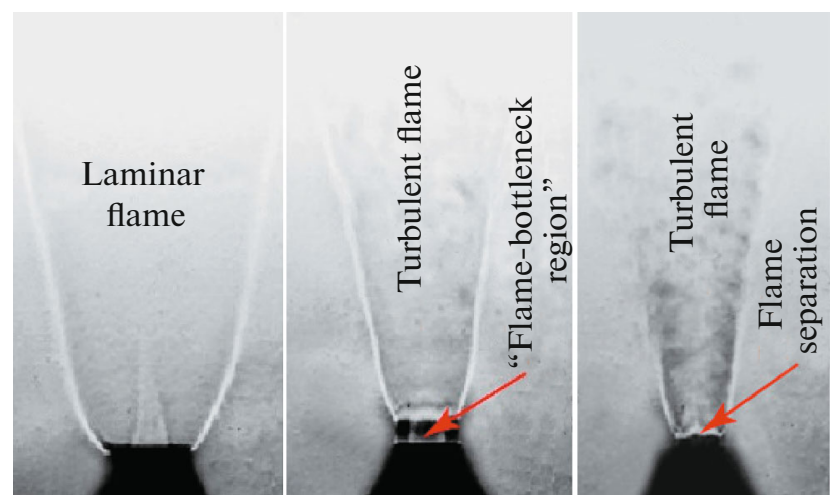

Fig. 2. Shadow patterns of development of the burning coaxial hydrogen jet (in the absence of the central air jet). and $S_{2}=4 \mathrm{~mm}^{2}$ is the area of the nozzle-apparatus coaxial slot from which hydrogen is supplied $(\varnothing=$ $4.0-4.6 \mathrm{~mm})$.

\section{EXPERIMENTAL RESULTS}

\section{Scenario for Diffusion Combustion of a Hydrogen Jet Outflowing from an Annular Nozzle into a Flooded Airspace}

The results of experiments on the combustion of a ring (coaxial) hydrogen jet with increasing velocity of its outflow up to supersonic speed are shown in Fig. 2.

At low outflow velocity of the jet, one can observe the presence of the laminar flame, the boundary of which expands under a noticeable angle. As the jet velocity increases, the region of the "flame bottleneck" appears, when the flow in the flame is turbulized in a narrow region just as in the case of a hydrogen jet flowing from a round nozzle; however, in this situation, we observe no spherical shape, and the resulting region represents a hollow cylinder attached to the nozzle with an outside diameter larger than the diameter of the coaxial nozzle. The character of the gas flow in the region of this cylinder is laminar. With a further increase in the flow velocity, the laminar part of the flame in the cylinder disappears and we observe the separation of the turbulent flame from the nozzle cutoff.

We consider the diffusion combustion scenarios when a supersonic jet of air outflows in the center of the nozzle. 


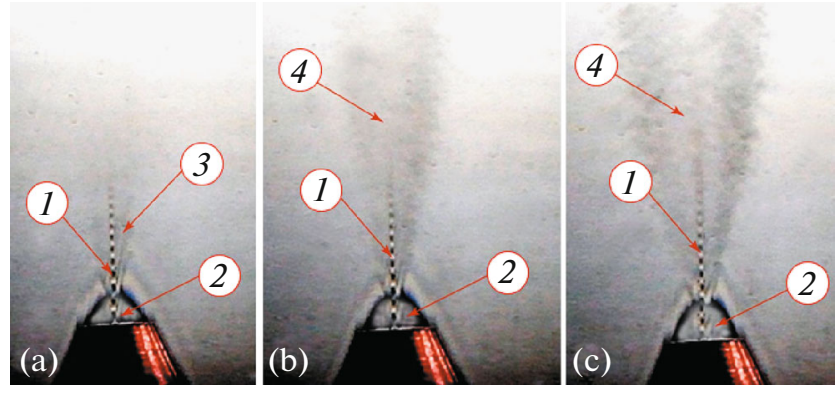

Fig. 3. Shadow patterns of the interaction between the burning coaxial hydrogen jet and the round microjet of air during its supersonic flow: 1 is the supersonic cells on the round microjet of air, 2 is the region of the "closed" hydrogen flame, 3 is the hydrogen outflow from region 2 without combustion, and 4 is local ignition and unstable combustion.

\section{Scenarios of Combustion of a Hydrogen Jet Outflowing from an Annular Nozzle in the Presence of a Microjet of Air Outflowing at Supersonic Velocity in the Center}

The process of development of the flame-bottleneck region, its specific shape, and the transformation with increasing velocity of the coaxial jet outflow in the presence of a supersonic air jet are shown in Figs. 3 and 4 . The central air microjet outflows at a constant supersonic velocity as is evidenced by small-scale supersonic cells, which are also observed in the resulting flow in the presence of a coflowing ring jet of hydrogen (with combustion and without it).

At low hydrogen outflow rates from the coaxial nozzle and with ignition near the nozzle, instead of a hollow laminar cylinder attached to the nozzle, a cone-like structure arises, the boundaries of which are clearly visible in the image patterns (black lines), and combustion occurs within it, and, further, the gas mixture extending beyond the borders of the cone apex is not ignited, and it occurs over a wide range of hydrogen flow rates; i.e., there is a "locking" of the flame in this cone-shaped region (see Fig. 3a).

In Figs. $3 b$ and $3 c$, we show the moment of the gasmixture ignition in the upper part of the jet, which is accompanied by the generation of intense acoustic noise. In this case, the images show the appearance of new shock waves (gas density gradients) throughout the cone.

The further development of the scenario of hydrogen coflowing ring combustion with an increase in the flow velocity is shown in Fig. 4. The laminar section of the flame develops and acquires a spherical shape covering the supersonic part of the air jet, and, then, with a further increase in the hydrogen flow rate, its boundaries are blurred and it disappears; we observe only the turbulent section of the flame.

In general, we can conventionally distinguish the following stages of the combustion of a coflowing ring jet of hydrogen in the presence of a supersonic air jet

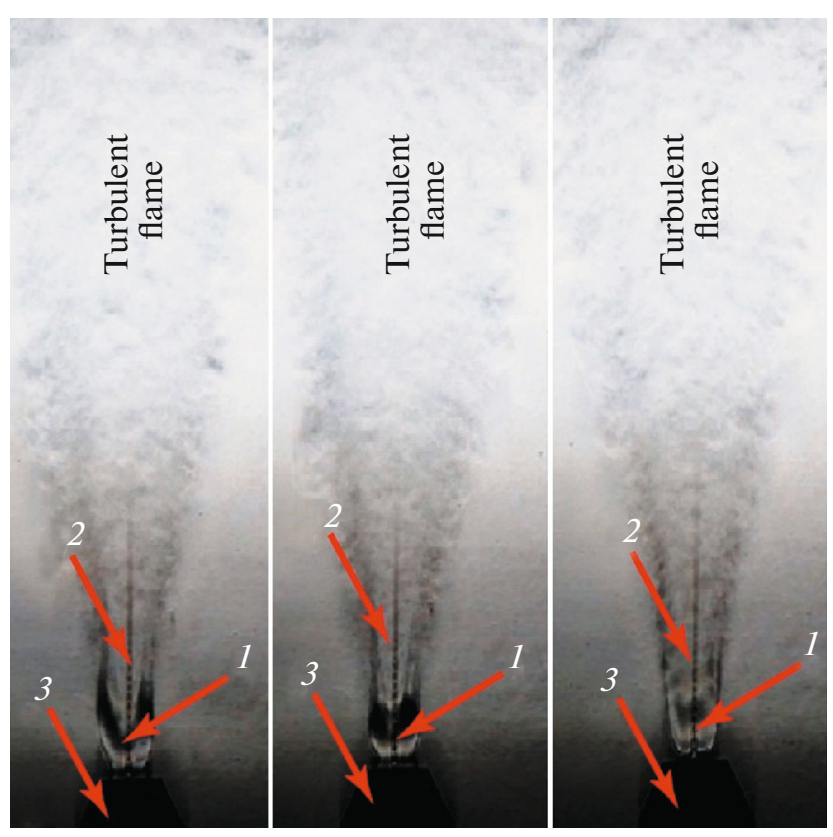

Fig. 4. Shadow patterns of the interaction between the burning coaxial hydrogen jet and the round air microjet during subsonic and supersonic flow from the outlet nozzle: 1 is the laminar flame section, 2 is the supersonic cells on the round microjet, and 3 is the burner nozzle.

in the center depending on the hydrogen outflow velocity.

(i) At the initial stage, with a low hydrogen-outflow velocity and the ignition near the nozzle, the flame combustion is "locked" in the cone-shaped region attached to the nozzle. We observe the combustion near the nozzle cutoff bounded by a cone-shaped region with a supersonic air jet "cutting through" the top of this cone, and the mixture of air and hydrogen is ejected through this "breakthrough," but with no combustion.

(ii) As the hydrogen flow rate increases, the flame spreads downstream, and the local combustion areas begin to form, an acoustic noise appears, and the cone-shaped region is transformed into a hemisphere.

(iii) Stable turbulent combustion is established and develops accompanied by the generation of intense acoustic noise, and laminar sections surrounding the supersonic air jet arise near the nozzle cutoff.

(iv) Further, the turbulent flame zone shifts closer to the nozzle cutoff and the laminar section of the flame is blurred and disappears.

As the hydrogen flow rate decreases, a reversible transition from stage (iv) to stage (i) occurs sequentially; all combustion scenarios are preserved.

\section{CONCLUSIONS}

It was found that the diffusion combustion of a single hydrogen jet outflowing at a subsonic velocity from 
an annular micronozzle into a flooded space is also characterized by a combustion scenario with the presence of a flame "bottleneck" region as for the round and flat microjets [1-5]. However, the flame-bottleneck region undergoes significant geometric deformations due to the specificity of the coaxial jet flame.

In the presence of air in the center of the supersonic microjet, the combustion of the coaxial hydrogen jet changes significantly. The following scenarios were found to be implemented sequentially with an increasing hydrogen flow rate:

(i) "locking" of hydrogen combustion in the coneshaped region and the ejection of the hydrogen and air mixture downstream in the absence of combustion (which can be applied to premixed gas mixtures);

(ii) formation of a hemispherical flame region near the nozzle cutoff and the local unstable combustion of turbulent flow;

(iii) a laminar flame of spherical shape near the nozzle cutoff and the established turbulent combustion downstream;

(iv) a developed turbulent flame starting from the nozzle cutoff.

Also in this case, we observe no decrease in the spherical flame zone as the hydrogen flow rate increased as occurred in [1-5].

\section{FUNDING}

This work was supported by the Ministry of Science and Higher Education of the Russian Federation, project no. 075-15-2020-806.

\section{OPEN ACCESS}

This article is distributed under the terms of the Creative Commons Attribution 4.0 International Public License (http://creativecommons.org/licenses/by/4.0/), which permits unrestricted use, distribution, and reproduction in any medium provided you give appropriate credit to the original author(s) and the source, provide a link to the Creative Commons license, and indicate if changes were made.

\section{REFERENCES}

1. A. G. Shmakov, G. R. Grek, V. V. Kozlov, O. P. Korobeinichev, and Yu. A. Litvinenko, Vestn. NGU, Fiz. 10 (2), 27 (2015).

2. Yu. A. Litvinenko, G. R. Grek, V. V. Kozlov, O. P. Korobeinichev, and A. G. Shmakov, Vestn. NGU, Fiz. 10 (2), 52 (2015).

3. G. R. Grek, M. M. Katasonov, G. V. Kozlov, and M. V. Litvinenko, Vestn. NGU, Fiz. 10 (2), 42 (2015).

4. V. V. Kozlov, G. R. Grek, O. P. Korobeinichev, Yu. A. Litvinenko, and A. G. Shmakov, Dokl. Phys. 61, 457 (2016).

5. A. G. Shmakov, G. R. Grek, V. V. Kozlov, G. V. Kozlov, and Yu. A. Litvinenko, Sib. Fiz. Zh. 12 (2), 28 (2017).

6. V. V. Kozlov, G. R. Grek, G. V. Kozlov, Yu. A. Litvinenko, and A. G. Shmakov, Int. J. Hydrogen Energy 44, 457 (2019).

7. V. V. Kozlov, G. R. Grek, O. P. Korobeinichev, Yu. A. Litvinenko, and A. G. Shmakov, Int. J. Hydrogen Energy 41, 20240 (2016).

8. V. V. Kozlov, G. R. Grek, G. V. Kozlov, Yu. A. Litvinenko, and A. G. Shmakov, Sib. Fiz. Zh. 12 (3), 62 (2017).

9. G. T. Kalghatgi, Combust. Sci. Technol. 41, 14 (1984).

10. Yu. M. Annushkin and E. D. Sverdlov, Fiz. Goreniya Vzryva, No. 5, 53 (1978).

11. V. Shentsov, R. Sakatsume, D. Makarov, K. Takeno, and V. Molkov, in Proceedings of the 8th International Seminar on Fire and Explosion, Hefei, China, 2016.

12. A. G. Shmakov, G. R. Grek, V. V. Kozlov, Yu. A. Litvinenko, and O. P. Korobeinichev, Vestn. NGU, Fiz. 11 (2), 56 (2016).

13. A. G. Shmakov, V. V. Vikhorev, G. R. Grek, V. V. Kozlov, G. V. Kozlov, and Yu. A. Litvinenko, Sib. Fiz. Zh. 13 (1), 54 (2018).

14. D. Guariglia and C. Schram, in Proceedings of the 2014 COMSOL Conference, Cambridge, 2014.

Translated by V. Bukhanov 